\title{
Research on Group Innovation and Crowd-Funding, Crowd-Sourcing of Wuhan
}

\author{
CAI guo-pei ${ }^{1}$ \\ Province of Hubei macroeconomic research institute, China \\ Cao ting ${ }^{2}$ \\ Business school of Jianghan University \\ Liang dong ${ }^{3 *}$ \\ Manufacturing Industry Development Research Center on Wuhan City Circle \\ Jianghan University
}

\begin{abstract}
Since the state is actively advocating group innovation, crowd-funding and crowd-sourcing, the research content of this article is to be able to respond to the national call for more people to participate. In this paper, we study methods of field investigation and literature collection and case comparison. The result of this study is that innovation needs to be innovated, transformed into new incubators and combined with education in colleges and universities. The most important thing is to strengthen the supervision and prevention measures. Crowdsourcing needs to improve the pricing mechanism and so on. In this paper, the research and innovation of this paper is new concept, new thinking and novel Angle of view. This paper discusses the present situation and problems of the three models of Wuhan group innovation and crowd-funding and crowdsourcing, and puts forward corresponding countermeasures and Suggestions.
\end{abstract}

Keywords-Group innovation; Crowd-funding; Crowdsourcing; Wuhan

\section{INTRODUCTION}

In recent years, Wuhan in order to implement the business plan of the CPC central committee to promote innovation, vigorously promote the construction of double innovation services, with the construction of marketization of enterprise operating mechanism and to speed up the space of developing, will the group innovation space into a national important base of innovative undertaking. On December 28, 2016, China launched its first "policy crowd-funding" in w-Wuhan east lake high-tech zone, aiming at the industrial policy of cultural and technological integration. This has epoch-making significance for the research of crowd-funding in Wuhan. Crowd-sourcing is essentially the company's job of distributing a job to its employees, but now it's distributed over the Internet, and more people are involved. The classic case of crowd-sourcing in Wuhan is the crowd-sourcing of Jing dong

\section{THE CURRENT SITUATION OF THE DEVELOPMENT OF GROUP INNOVATION AND CROWD-FUNDING AND CROWD- SOURCING IN WUHAN}

\section{A. The current situation of the development of group innovation in Wuhan}

Compared with the development of crowd-funding and crowd-sourcing model, the development time of group innovation in Wuhan is very early, and the current development situation is considerable. In 1987, the first technology enterprise incubator in China -- Wuhan east lake new technology entrepreneur service center -- was born in Wuhan, which opened the curtain on China's science and technology entrepreneurship service. Wuhan plays an important role in this technology entrepreneurship service.

First, the group innovation space is constantly expanding. So far, Wuhan east lake high-tech zone has been built incubator (accelerator) 53, national science and technology business incubators (accelerator) 15, the group innovation space, 64, 24 countries for the record the group innovation space, hatching area of 4.5 million square meters, gathered in the incubated enterprises more than 4000 , more than 3800 cumulative graduate enterprises, more than 500 business services. (Data source: marketization construction enterprise operation -- Wuhan east lake high-tech zone is speeding up the promotion of group innovation space construction technology department torch center Chen Qing)

Second, the dual - innovation service model is constantly innovating. From Wuhan east lake high-tech zone, four development has realized the innovation of scientific and technological achievements: from research and development of the campus, the promotion to the colleges and universities around the hatch, to develop industrialization of university science park, eventually become a large-scale high-tech industrial parks. [2]"

Third, diversity of group innovation space. Through the construction of the space, to further enlarge the Wuhan east lake high-tech zone policy "experimental field" effect, provide good working space for innovative entrepreneurs, network space, social space and resources sharing space. In 2016, 16652 
new market entities were added, up $29 \%$ from the same period last year, and 12,614 new enterprises, up 28.8\%, and the average number of new enterprises was 51. So far, Wuhan east lake high-tech zone has registered 7230,000 market participants. (Data source: marketization construction enterprise operation -- Wuhan east lake high-tech zone is speeding up the promotion of innovation space construction technology department torch center Chen Qing)

Fourth, innovation and entrepreneurship activities are soaring. Wuhan east lake high-tech zone held each year, thousands of innovative entrepreneurial activity, average daily reach six "double gen" activities, Qing Hui" optical valley" "east lake" guest hui "and a series of high level" double gen "activities in Wuhan and even domestic have good response. Wuhan East Lake high-tech zone is dedicated to making innovation a life and a culture. Build a culture of "encouraging innovation and tolerance failure. [2]"

\section{B. The current situation of the development of crowd-funding in Wuhan}

The most typical crowd-funding model in Wuhan is "government crowd-funding". This is not only the Wuhan east lake high-tech new area first launch, in the whole country also is rare. Of the whole country at present the raise pattern in Tianjin, Xiamen, 3 cities are supported by local governments, such as platform, but the government support is mostly in resources environment platform, the raise and the launch of Wuhan government should belong to the only one the functions of the government personnel selection to the entrepreneur, is completely belongs to the people to participate in the raise. The "Internet +" industrial development office, established in the east lake high-tech zone of Wuhan city, is open for the selection of staff members. Each of them wrote an article about the development of the Internet, which was then selected by the examiner. The interviewers, from major Internet companies in Wuhan, asked the interviewees to describe their views and opinions on the development of the Internet industry in five minutes and their own liking. After the interview, the owners of Internet companies will also give the government some opinions and views on the development of the Internet + industry development office. The "crowd-funding" approach is to select people for government and collect their ideas. And the planning of the "Internet + " industrial development office is only the beginning. The ultimate goal of the East Lake hightech zone management committee is to transform into an Internet government. And the domestic initiative of the charity medical crowd-funding platform is also launched in Wuhan. The provincial charity association has developed a crowdfunding platform for charitable medical care, which is the first time in China to achieve a seamless connection between medical crowd-funding and hospital charging system. The patient pays the medical bills directly by using the mobile phone on the crowd-funding platform. You can raise the cost, use the cost, don't wait. And the fees can be used immediately, without any proof of writing. Eventually, the provincial charity will always be settled with the hospital, not personally. There are some of the raised platform in developing, financing the raised platform, such as Wuhan is raise has the largest and widest coverage the raised amount, and is one of the most ground project below the raised platform [3][5].

\section{The Current situation of the development of crowd- sourcing in Wuhan}

The concept of crowd-sourcing came into public view in 2006 when a foreign journalist published the article about crowd-sourcing. But it was not until 2008 to complete the definition of crowd-sourcing: crowd-sourcing is the traditional should be performed by internal staff mission, through Internet or other public mode of outsourcing to the masses. Therefore, crowd-sourcing mode in Wuhan is relatively late and immature.

Jing dong "express crowd-sourcing" is the crowd-sourcing business card of Wuhan. Jing dong crowd-sourcing is a social delivery service mode, which is a new and accurate logistics method based on LBS positioning. Whether company workers, white-collar workers, students, Internet or square dance elderly men, as long as through the training, can grab a single, complete around 3 to $5 \mathrm{~km} 2$ hours and distribution of goods. Take Wuhan as an example: since its launch in July 2015, Jing Dong crowd-sourcing has been developing rapidly. As of early September, "Jing dong crowd-sourcing" APP has attracted more than 15,000 registered users and about 10,000 active users. (Data source: Wuhan Jing Chu network) and the crowdsourcing website platform in Wuhan is still relatively backward, without attracting much attention. China's more successful crowd-sourcing network platform is the pig eight quit net and task China network. But here, clinch a deal the task mostly from small and medium enterprises, more complex, not many technical difficult task, the proportion is the largest enterprise for logo, signs, slogans, such as creative tasks. Therefore, the development of crowd-sourcing in Wuhan is relatively new, not mature [4] [6].

\section{THE PROBLEM OF GROUP INNOVATION AND CROWD- FUNDING AND CROWD-SOURCING IN WUHAN}

\section{A. The problem of group innovation in Wuhan}

\section{1) Shortage of new incubators}

Currently in Wuhan of the group innovation space, is to provide innovative entrepreneurs entrepreneurship weak environment, and actually what we call soft environment, such as giving entrepreneurs to certain ideas, inspiration, communication and so on, these are all very lack [1].

2) The rapid expansion of all the group innovation space causes the management team and the professional quality to be difficult to match the support

Due to insufficient preparation, such as: lack of field work to don't know the regional differences, positioning are not allowed to cause the service ability is not enough space, planning is not considerate lead to allocate resources, the basis of hardware facilities are congruent. The creation space is easy to make "aerial shop", his professional degree is extremely reduced. Because, on the other hand, planners and organizers concept deviation, put the gen space as unused items of space, has caused many people to the blind construction and space, excess supply of resources, and caused a lot of waste of resources. In Wuhan, many creative Spaces enter universities 
to guide students to submit ideas, eventually requiring students to pay some money, and he will give the college student a certificate of entrepreneurship and innovation. In fact, this kind of practice has not experienced the creative connotation at all, and the level of creative space is very low. This phenomenon is common in Wuhan University.

\section{3) There is less precipitation among college students}

The number of college students in Wuhan is the largest in the country, and there are not many of them combined with education. Even many colleges don't have space to hatch. And due to the large area of Wuhan, the area of mass group innovation space is scattered. Generally requires college students' independent innovation entrepreneurship at present the country, but the Wuhan student Numbers, most universities is the most, but the data show that many college students don't know what the space, what is the incubator. Therefore, in the university education, there is not enough knowledge about entrepreneurship and entrepreneurship.

\section{B. The problem of crowd-funding in Wuhan}

\section{1) Fraud high}

In Wuhan raise is the most common friends and relatives around us all the needed the money in the circle of friends and various social networking sites by raise, because in fact in the network have a lot of false information, so this will result in a high incidence of fraud. Fraud is one of the most problematic and most suspect. Crowd-funding platforms have become the new way to invest fraud because the threshold for crowdfunding investment is low. For all the raise, unlike traditional angel investment, on the raised platform, generally no personal contact between investors, to participate in the investment of the project or the sponsor of the project or enterprise is also don't understand. There is also a reason why investors are not able to monitor the operation of the project because of the geographical separation of investors and investors, which greatly increases the risk of fraud.

\section{2) Investors are more difficult to protect}

Due to the almost majority of the crowd-funding platforms in Wuhan as the online platform, it is difficult to protect investors. Crowd-funding, as a new model of Internet finance, has different forms of financing and risk points than traditional financing methods. The majority of investors to raise the risk of the all have no good idea, even the lack of participation by the raise of themselves project is good or bad judgment easily under the induction of others or by simply judging on the interest rates make the wrong choice. In April 2013, only one month after the launch of the "crowd-funding network" announced the collapse. The announcement said that because of the lack of investment risk and lack of investment experience, investors caused huge losses. China's lack of supervision over the Internet has made it more difficult to protect investors. At present, the roll call time is taken first pay to collect, and then through the legal way to punish the money to the project sponsor shall pay, just too late, but this way is not a long-term solution. And the Wuhan government crowdfunding is a very meaningful event, so that governmentsponsored crowd-funding will make it easier for investors to protect themselves.

\section{3) Easy involvement in illegal financial activities}

The crowd-funding model is actually very similar to what it means to raise money. It is not hard to imagine crowd-funding very easy to get involved in illegal financial activities. Crowdfunding I understand is actually a kind of more networked virtual money trading behavior. This can easily lead to illegal financial transactions, such as money laundering and other illegal activities. Ordinary people are involved in a crowdfunding campaign, and all are online transactions, but there is also the risk of exposing their internal information.

\section{The problem of crowd-sourcing in Wuhan}

\section{1) Lack of pricing model}

Now crowd-sourcing sites have two types of reward, one for which the task issuer is fixed and the other to bid by the recipient. Most of the task pricing on crowd-sourcing websites is determined by the employer, which is the provider of the task, and only bidders who can accept the pricing will participate in the bid. Take Wuhan Jing dong crowd-sourcing as its pricing mechanism, and make a profit of 6 Yuan for a single order on jd.com. The quantity of the daily order is 5 , the additional 6 Yuan reward; you can get 30 Yuan for the above 20. (Date source: Wuhan Jing Chu network). Although this mechanism is good for a lot of people to make money, but may be different logistics companies of the same nature of the business will price difference is very big, even in the same company project because of the time, season, weather and so on the outside and the reasons cause the price also differs very big. So in this case the consumer price gap is very large, and the participants are dissatisfied because of the difference in price. So there is no standard for crowd-pricing, which can lead to many problems [6].

\section{2) Environmental factors are complicated}

Wuhan is a vast area with two rivers and four Banks. The roads are complex, the location is difficult and the climate is changeable. Because the package is a company or organization in the past by employees perform work tasks, in the form of free voluntary outsourced to non-specific (and usually large) the practice of the public network, and the public network is composed of don't know each other friends, is called the contractor. The complexity of environmental factors makes the task of limiting time must build multiple service stations. For example, for crowd-sourcing, the contractor needs to work outdoors for a long time, while the weather in Wuhan is bad, and the temperature of winter and summer is large, and it often rains to the crowd.

\section{3) Consumer's watching}

Consumers have an aversion to crowd-sourcing, since Wuhan's Internet penetration is lower than that of first-tier cities such as Beijing, and consumers also lack $\mathrm{O} 2 \mathrm{O}$ consumption experience. Although the network is more developed now, many people still have a skeptical attitude towards registering some of the Internet, and the popularity of the people is still not high. They also tend to be more resistant to the registration of crowd-sourced packages, and are afraid to expose their own information to risk exposure. 


\section{THE STRATEGY OF GROUP INNOVATION AND CROWD- FUNDING AND CROWD-SOURCING IN WUHAN}

\section{A. The strategy of group innovation in Wuhan}

1) The countermeasures of implementing the new incubator are five ideas: one: to transform the traditional incubator into a new incubator, and to improve the hardware facilities according to the innovation and entrepreneurship category. Secondly, we can make full use of the advantages brought by the current "Internet plus" and use the mobile ecommerce platform to carry out online and offline services to achieve "Internet + innovation and entrepreneurship". Third, we should strengthen the principle of guiding entrepreneurship, implement the spirit of entrepreneurship and strengthen the work of entrepreneurship. Fourth: to organize various forms of innovation and entrepreneurship projects and competitions, and create an atmosphere of group innovation space construction. Fifth: strengthening the communication among the group innovation subjects is also the key point of the incubator startup culture.

2) There are two countermeasures to the decline of specialization. First, create a group innovation monitoring and management center to manage all kinds of group innovation space in Wuhan and group innovation projects, and evaluate the professional ability of the group innovation space. Second, strengthen government guidance and public participation. The government in the space which actually should be served as an important role, the government controls the execution, can reduce the professional team, in which public participation can make people more people to control, also can let people to participate in understanding this new business model.

3) Ascend the main measures and consciousness in the precipitation of the college students in colleges and universities: first: we should combine innovation and entrepreneurship theory with education of the subject, and create the innovation program in university, and combine innovation with college innovation credits. Secondly, it is necessary to make flexible management of college students and teachers and other groups, so as to select and cultivate entrepreneurial projects, so as to create a platform suitable for university students and teachers. Universities can build a pioneer park or a start-up community. At present, central China normal university has established the first college student entrepreneurship zone in the university, aiming to improve the innovation and entrepreneurship enthusiasm of university students. Third, establish an exchange with the regional university entrepreneurship alliance. Because of Wuhan university, area is larger, distribution is more scattered, so it's best to put with the university, or similar, of the university of home-based business alliance, regular exchange ideas and learn, that not chaotic.

\section{B. The strategy of crowd-funding in Wuhan}

1) The strategy of preventing fraud: clear division of regulatory agencies and coordination. Different types of crowdfunding models have different regulatory bodies. Because crowdfunding comes in several forms, such as the crowdfunding of equity model, crowdfunding of lending patterns. The crowdfunding of equity mode should be regulated by corresponding financial markets or securities; However, the crowdfunding of lending mode has no uniform regulatory mode in China. The most important thing about this kind of deception is the regulatory regime. But at the same time, because crowdfunding is a relatively new market model, the current regulation in China is not comprehensive enough, so more investors need to strengthen their own awareness.

2) The strategy of protection for investors: first, use government support to strengthen supervision, in which the government is a third-party regulatory platform and a support platform. Second: crowd-funding agencies organize activities to explain the knowledge of self-investment protection to investors and prevent fraud.

3) The countermeasures to avoid financial risks: guide the healthy development of the industry and avoid the legal red line of stampeding illegal fund-raising and illegal securities activities. Different modes of crowd-funding have different legal risks and need to actively guide market players to participate rationally and avoid illegal activities in the industry. In the lending mode, the network loan platform is divided into "intermediary" and "self-supporting". The former is engaged in the information matching business, does not involve in the transaction itself, does not absorb investors' funds, and does not raise funds; the latter makes financial products, sells them to the public through offline channels, absorbs investors' funds and is suspected of illegal fund-raising. Therefore, it is possible to encourage the formal operation of the "intermediary" platform and set loose regulation rules. For the "selfsupporting" platform, we should implement the licensing system and strictly regulate its operation activities.

\section{The strategy of crowd-sourcing in Wuhan}

1) The pricing model of the default solution: website can clinch a deal on the original task on the basis of the investigation, to a reasonable classification task, some properties of similar tasks, combined with market research, on the basis of the current market price can be appropriate regulations, reasonable price range. This solves the disadvantages of the party's unilateral pricing and leaves some reasonable room for adjustment, and also provides some reference for the bidding of the task participant. Temporary crowd-sourcing can also be established in response to severe weather conditions, allowing contractors to shelter from the rain and to communicate with each other temporarily.

2) Countermeasures for dealing with complex environment: Wuhan complex geographical conditions, mainly to Han Kou, Wu Chang, Han Yang is complementary to do promotion of office buildings, residential areas, increase of the 
package in the area of activity and influence, and inter-district longitudinal radiation citywide [6].

Guide countermeasures of consumers: The issuing task force implements one-to-one guidance, carries out face-to-face instruction to consumers, and strengthens knowledge of crowdsourcing. Using the Internet government to publicize the knowledge of crowd-sourcing to make people more confident.

\section{CONCLUSION}

Through three kinds of model studies, i.e., the shortage of group innovative incubator, and lack of specialization degree to the combination of three questions, as well as the raise of fraud rate is high, not enough protection of investors and easy to get involved in illegal financial activities of the three questions, and crowd-sourcing pricing model is insufficient, the external environment factors and consumer attitude toward crowdsourcing three problems, this article put forward the corresponding countermeasures. Three new types of innovation and entrepreneurship are new in China at present, but I believe that in the future, it will become the mainstream way of innovation and entrepreneurship.

\section{ACKNOWLEDGMENT}

Fund source:

IWIIS2016468 Wuhan institute of Jianghan University 2016 open fund

WZ2016Y03 Hubei humanities and social science key research base - Manufacturing Industry Development Research
Center on Wuhan City Circle, Jianghan University2016 open fund

About the authors:

Caiguopei, 1966-, a researcher at the Hubei institute of macroeconomics, has long been involved in financial management and corporate financing.

Cao ting, 1996 -, department of, Wuhan in the province of Hubei, as corresponding author

Liangdong, 1960-, professor in business school of Jianghan University, reasecher in Manufacturing Industry Development Research Center on Wuhan City Circle, Jianghan University. As corresponding author.

\section{REFERENCES}

[1] Xu rujun: "13th five-year plan" period of the construction of the construction and development mode of the area 2016.10. (In Chinese)

[2] Chen Qing's market-oriented construction enterprise operation -- Wuhan east lake high-tech zone to accelerate the construction of all creative space 2017.04. (In Chinese)

[3] See how Wuhan east lake USES Internet thinking to run government 2015.06. (In Chinese)

[4] Gao yun and Cui jinghong: Study on the development status of crowdfunding website. (In Chinese)

[5] Mr. Zhou policy the raise to redefine the "dc" a high-tech industry center of Wuhan east lake high-tech zone to launch domestic first "policy and the raise" 2016.12. (In Chinese).

[6] The three challenges facing jd.com's crowd sourcing model in wuhan. (In Chinese) 